DE

M E D I C I N A

T R O P I C A L

DE

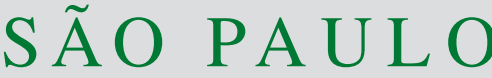

JOURNAL OF THE SÃO PAULO INSTITUTE OF TROPICAL MEDICINE

${ }^{1}$ Universidad de Guadalajara, Centro Universitario de Ciencias de la Salud Guadalajara, Departamento de Microbiología y Patología, Guadalajara, Jalisco, Mexico

Universidad de Guadalajara, Centro Universitario de los Valles, Departamento de Ciencias de la Salud, Ameca, Jalisco, Mexico

${ }^{3}$ Universidad de Guadalajara, Centro Universitario de Ciencias de la Salud, Departamento de Biología Molecular y Genómica, Guadalajara, Jalisco, Mexico

${ }^{4}$ Secretaria de Salud Jalisco, Centro de Salud Tonalá, Guadalajara, Jalisco, Mexico

${ }^{5}$ Universidad de Guadalajara, Centro Universitario de la Ciénega, Departamento de Ciencias Médicas y de la Vida, Ocotlán, Jalisco, Mexico

Correspondence to: Iván Isidro Hernández Cañaveral

Universidad de Guadalajara, Centro Universitario de Ciencias de la Salud Guadalajara, Departamento de Microbiología y Patología, Sierra Mojada 950, Col Independencia, CP 44340, Guadalajara, Jalisco, México Tel: +52 1-3699 0509, +52 1-21546926

E-mail: ivanhzc21@yahoo.com.mx

Received: 1 March 2021

Accepted: 26 May 2021

\section{Association of TAP1 1177A $>G$ and 2090A $>G$ gene polymorphisms with latent tuberculosis infections in sheltered populations, in the metropolitan area of Guadalajara, Mexico: a pilot study}

\author{
Gerardo Cazarez-Navarro', Jaime Palomares-Marín', Sergio Yair Rodríguez-

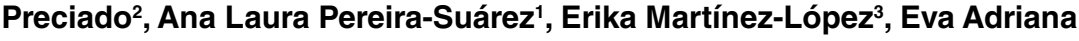 \\ Bacilio-Medrano ${ }^{4}$, Selene Huerta-Olvera ${ }^{5}$, Iván Isidro Hernández-Cañaveral ${ }^{(1}$
}

\section{ABSTRACT}

Latent tuberculosis infection (LTBI) is a condition that has no clinical signs and symptoms. LTBI patients are characterized by persistent immune responses to Mycobacterium tuberculosis, and approximately 5-10\% of these infected individuals will develop active TB at some point in their lives. The antigen transporter associated with antigen processing (TAP1) is a protein involved in the transport of the antigen from the cytoplasm to the endoplasmic reticulum by means of the association with MHC class I molecules. It plays a fundamental role in the immune response, promoting the clearance of intracellular pathogens. Our pilot study aimed to determine the association between TAPl gene 1177A $>\mathrm{G}(\mathrm{rs} 1057141)$ and 2090A $>\mathrm{G}$ (rs1135216) genetic polymorphisms with susceptibility to LTBI. In this case-control study, 153 individuals from shelters were analyzed (46 were LTBI-positive and 92 were controls). Genotyping of the rs11352216 (2090A >G) and rs1057141 (1177A >G) gene IDs was performed using the Applied Biosystems Step One Thermal Cycler Real-Time PCR allelic discrimination technology. The haplotypic analyses were performed with the Arlequin 3.5 program. Social assistance centers and shelters that serve vulnerable populations represent high-risk sites due to overcrowding and the impaired nutritional status of their residents. The $\mathrm{G}$ allele $(\mathrm{OR}=1.99, \mathrm{CI}=1.109-3.587$, $p=0.021)$ and the GG genotype of $\operatorname{rs} 11352216(\mathrm{~A}>\mathrm{G})$ were associated with susceptibility to LTBI, according to the codominant genetic model $(\mathrm{OR}=8.32, \mathrm{CI}=1.722-61.98, p=0.007)$. The rs1057141 $(\mathrm{A}>\mathrm{G})$ polymorphism was not associated with LTBI risk. The results suggest that carriers of the $\mathrm{G}$ allele of rs1135216 (A>G) are susceptible to LTBI.

KEYWORDS: Latent tuberculosis infection. Genetic susceptibility. Mycobacterium tuberculosis. TAP1.

\section{INTRODUCTION}

Tuberculosis (TB) is a public health problem and a threat to human health worldwide, given that it is one of the global top ten causes of death. According to 2019 World Health Organization (WHO) estimates, 10 million people fell ill with TB, approximately 1.5 million died, and about three million were undiagnosed ${ }^{1}$. In Mexico, there was an increase of 30,000 new cases of tuberculosis ${ }^{2}$. Therefore, tuberculosis in Mexico continues to be a public health challenge, requiring redoubled efforts.

Individuals that are in continuous contact with patients with active TB appear to have a higher risk of latent tuberculosis infection (LTBI). LTBI is due to Mycobacterium tuberculosis (Mtb) and is a medical condition in which patients do 
not develop clinical signs or symptoms. It can also progress to active $\mathrm{TB}$ or persist for years in the host. In addition, these patients do not transmit the disease and are characterized by the presence of persistent immune responses to $M t b$ antigens ${ }^{3}$. About one-quarter of the world's population is estimated to present with $\mathrm{LTBI}^{2}$ and 5 to $10 \%$ of these individuals will progress to active $\mathrm{TB}^{4}$.

Several factors increase the risk of developing active TB, such as the overcrowded living conditions present in shelters and prisons, malnutrition, drug use, prolonged therapy with corticosteroids, and the occupational exposure of health workers, mainly in countries with a high incidence of TB and in developing countries ${ }^{5}$.

Moreover, individuals with diabetes have a 3 -fold increase in the risk of developing active TB and individuals with the human immunodeficiency virus (HIV) infection have 16 to 27 -fold higher risk ${ }^{1,5}$.

Genetic association studies have reported that the presence of different polymorphisms in the VDR, IL12, IFNG, TAPI and TAP2 genes generates susceptibility to mycobacterial infections $^{6-8}$. The TAP1 rs1057141 and rs1135216 single nucleotide polymorphisms (SNPs) have been associated with susceptibility to active TB, but no studies have explored the association of these SNPs with $\mathrm{LTBI}^{7,8}$.

TAP1/TAP2 are proteins that form the transporter associated with the antigen processing (TAP) and they are encoded by the TAP1 and TAP 2 genes located on chromosome 6 in the major histocompatibility complex (MHC) region ${ }^{9}$. TAP proteins play a fundamental role in the immune response to promote the clearance of intracellular pathogens, such as $M t b . M t b$ has developed different virulence factors that allow it to evade lysosomal degradation within infected macrophages, and thus avoiding the MHC-II antigen presentation pathway ${ }^{10}$. That action leads to the release of bacterial antigens into the cytosol, and then the process continue following the ubiquitinproteasome pathway ${ }^{11}$. The antigenic peptides generated are transported to the lumen of the endoplasmic-reticulum by TAP1/TAP 2 proteins for cross-presentation ${ }^{12}$. Therefore, cross-presentation will be the last mechanism of the cellular response to eliminate the bacillus ${ }^{13}$.

The aim of the present pilot study was to investigate the possible association of the rs 1057141 and rs 1135216 genetic polymorphisms in the TAPl gene with susceptibility to LTBI.

\section{MATERIALS AND METHODS}

\section{Subjects and sample collection}

The 153 study participants were recruited from shelters offering social assistance in metropolitan areas of Guadalajara, Mexico, during 2019. Fifteen of the 153 subjects were excluded because they did not fit the study criteria (comorbidities, such as HIV infection, diabetes mellitus, autoimmune diseases, and subjects with indeterminate QuantiFERON-TB Gold Plus - QFT-Plus results). Forty-six subjects were included and all of them were LTBI-positive. The control group was composed of 92 healthy subjects that had no known records of TB exposure, had a negative QFT-Plus test, and no clinical or radiological evidence of TB. Blood samples were drawn from LTBI cases and control subjects, in ethylene-diaminetetra-acetic acid (EDTA) and lithium-heparin tubes, for DNA extraction and evaluation by the QFT-Plus test.

\section{Ethical issues}

The present study was reviewed and approved by the Ethical Investigation and Biosecurity Committee of the University Center of Health Sciences at the University of Guadalajara (approval CI-04218). The research was performed according to the Declaration of Helsinki and the Mexican regulations. Informed consent was signed by all the individuals.

\section{LTBI evaluation}

LTBI evaluation was performed through an interferongamma release assay (IGRA), using QFT-Plus (QIAGEN, Hilden, Germany) to measure responses to ESAT-6 and CFP-10 peptide antigens. Blood containing lithium-heparin as anticoagulant was transferred to the QFT-Plus tubes (Nil-tube, TB1-tube, TB2-tube, and Mitogen-tube). A test was considered positive when, of the four tubes (Nil, TB1, TB2, Mitogen), either the TB1-tube or the TB2-tube presented with a value higher than the Nil IFN- $\gamma$ IU/mLone. Subjects were considered LTBI-positive if they had a positive QFT-Plus test with no clinical or radiological evidence of active TB disease ${ }^{14}$.

\section{DNA extraction}

Genomic DNA was extracted from peripheral blood leukocytes of the cases and controls, using the High-Pure PCR Template Preparation Kit (Roche Molecular Systems, Indianapolis, USA), as described elsewhere.

\section{Polymorphisms}

The identification of SNPs was carried out through RealTime PCR using the allelic discrimination technology. The polymorphisms were identified by primers and Taqman ${ }^{\mathrm{TM}}$ 
hydrolysis probes for each of the SNPs specific to the wild-type and the polymorphic forms, using TAPl gene ID rs1135216 (2090A>G), Cat_\#531909_20; TAP1 rs1057141 (1177A $>$ G), Cat_\#549926_20, (Applied Biosystems ${ }^{\mathrm{TM}}$, Foster City, USA), FastStart Essential DNA Probes Master (Roche Molecular Systems, Indianapolis, USA, catalog number 06402682001). The amplification reaction was performed in a StepOne ${ }^{\mathrm{TM}}$ Thermal-Cycler (Applied Biosystems $^{\mathrm{TM}}$, Foster City, USA).

\section{Statistical analysis}

The genotypic and allelic frequencies of the polymorphisms were determined by direct counting. The Hardy-Weinberg equilibrium in the controls was determined using the chi-square test $\left(\chi^{2}\right)$. The distributions of the genotypes and allele frequencies in both groups (LTBI cases and controls) were analyzed using the $\chi^{2}$ test. Non-parametric quantitative determinations, odds-ratio $(\mathrm{OR})$ and $95 \%$ confidence interval $(95 \% \mathrm{CI})$ were used to analyze the risk for LTBI associated with the TAPI gene polymorphism. To evaluate the effect of both polymorphisms on LTBI, we used genetic inheritance models and haplotypic analyses. The statistical analysis was performed using the Arlequin software, version 3.5 (University of Bern, Germany), the SPSS Statistics for Windows, version 25.0 (IBM, Armonk, New York, USA) and the OpenEpi.com Statcalc (Andrew G. Dean and Kevin M. Sullivan, Atlanta, GA, USA). Statistical significance was set at a $p<0.05$, and the statistical power was $80 \%$.

\section{RESULTS}

\section{Population characteristics}

The participants were divided into two groups: 46 LTBI cases, and 92 healthy controls. The groups were paired two-to-one, and the male: female ratio and mean age were similar between the groups. The demographic features of the cases and controls are summarized in Table 1.

\section{Association between LTBI and TAP1 gene polymorphisms}

The genotypic and allelic frequencies of the TAP1 $1177 \mathrm{~A}>\mathrm{G}$ and $2090 \mathrm{~A}>\mathrm{G}$ polymorphisms in the LTBI cases and controls are shown in Table 2. The genotype frequency distribution of both polymorphisms in the controls was in the Hardy-Weinberg equilibrium ( $p=0.157$ and 0.56 , respectively). There were no statistical differences in the allele and genotype frequencies for the $1177 \mathrm{~A}>\mathrm{G}$
Table 1 - Demographic characteristics of LTBI cases and controls

\begin{tabular}{lccc}
\hline Characteristic & $\begin{array}{c}\text { Cases } \\
(\text { LTBI) }\end{array}$ & $\begin{array}{c}\text { Control } \\
\text { Subjects }\end{array}$ & $p$ \\
\hline $\mathbf{n}$ & 46 & 92 & \\
$\begin{array}{l}\text { Gender, n (\%) } \\
\quad \text { Male }\end{array}$ & $27(58 \%)$ & $52(56 \%)$ & 0.807 \\
$\quad$ Female & $19(42 \%)$ & $40(44 \%)$ & \\
Age (years) & & & \\
$\quad$ Mean & 21.4 & 22.6 & 0.631 \\
$\quad$ Range & $1-62$ & $1-69$ & \\
Age groups & & & \\
$\quad$ Children 1-11* & 13 & 19 & 1.0 \\
$\quad$ Teenagers 12-20* & 12 & 25 & 0.480 \\
$\quad$ Adults 21-44* & 16 & 39 & 0.272 \\
$\quad$ Elderly > 45* & 5 & 9 & 0.988 \\
\hline
\end{tabular}

$\mathrm{LTBI}=$ latent tuberculosis infection; *Age in years. $p$ values $<0.05$ were considered statistically significant.

polymorphism between the LTBI cases and controls. Regarding the $2090 \mathrm{~A}>\mathrm{G}$ polymorphism, we observed a statistically significant difference in the distribution of genotype frequencies $(p=0.013)$ between the study groups; individuals with LTBI presented a higher frequency of the GG polymorphic homozygote genotype than the controls ( $15.3 \%$ vs. $2.2 \%$, respectively). In addition, the $\mathrm{G}$ allele of the rs $1135216(2090 \mathrm{~A}>\mathrm{G}) \mathrm{SNP}$ was present in $30.4 \%$ of the cases, compared with $17.9 \%$ in the controls, with a statistically significant difference: $\mathrm{OR}=1.997,95 \%$ $\mathrm{CI}=1.109-3.587, p=0.021$ (Table 2).

When comparing the genotype frequencies of both groups $(p=0.007, \mathrm{OR}=8.328)$ for carriers of the $\mathrm{GG}$ genotype in the codominant model, we found a significant difference in the 2090A $>$ G SNP, as well as significant differences in the recessive and additive models (Tables 2 and 3 ).

In the inheritance model analysis by the Akaike Information Criteria for the 2090A $>$ G SNP, we found a value of 11.08 for the GG codominant model (Table 2).

The haplotypic association analysis was performed in both study groups to analyze the combined effect of the two polymorphisms in the TAP1 gene and no statistically significant differences were observed between the four haplotypes.

\section{DISCUSSION}

The subjects studied had a prevalence of LTBI of 30\%, consistent with reports from the WHO. The increased risk 
Table 2 - Distribution of genotypes (codominant Model) and alleles of TAP1 polymorphisms groups

\begin{tabular}{|c|c|c|c|c|c|c|c|}
\hline \multirow[t]{2}{*}{ Polymorphism } & \multicolumn{2}{|c|}{$\begin{array}{c}\text { Cases } \\
n=46\end{array}$} & \multicolumn{2}{|c|}{$\begin{array}{c}\text { Controls } \\
n=92\end{array}$} & \multirow[t]{2}{*}{ OR } & \multirow[t]{2}{*}{$95 \% \mathrm{Cl}$} & \multirow{2}{*}{$p$} \\
\hline & $\mathrm{n}$ & $\%$ & $\mathrm{n}$ & $\%$ & & & \\
\hline \multicolumn{8}{|c|}{ 1177A $>$ G (rs1057141) } \\
\hline \multicolumn{8}{|l|}{ Genotype } \\
\hline AA & 23 & 50 & 56 & 60.9 & & 1.0 & \\
\hline$A G$ & 16 & 34.8 & 30 & 32.6 & 1.296 & $0.587-2.833$ & 0.516 \\
\hline GG & 7 & 15.2 & 6 & 6.5 & 2.805 & $0.824-9.807$ & 0.098 \\
\hline \multicolumn{8}{|l|}{ Allele } \\
\hline$A^{a}$ & 62 & 67.4 & 142 & 77.2 & & 1.0 & \\
\hline $\mathrm{G}$ & 30 & 32.6 & 42 & 22.8 & 1.633 & $0.93-2.85$ & 0.086 \\
\hline Total & 92 & 100 & 184 & 100 & & & \\
\hline \multicolumn{8}{|c|}{$2090 A>G($ rs1135216) } \\
\hline \multicolumn{8}{|l|}{ Genotype } \\
\hline AA & 25 & 54.4 & 61 & 66.3 & & 1.0 & \\
\hline$A G$ & 14 & 30.4 & 29 & 31.5 & 1.176 & $0.524-2.597$ & 0.685 \\
\hline GG & 7 & 15.3 & 2 & 2.2 & 8.328 & $1.722-61.98$ & 0.007 \\
\hline \multicolumn{8}{|l|}{ Allele } \\
\hline$A^{a}$ & 64 & 69.6 & 151 & 82.1 & & 1.0 & \\
\hline $\mathrm{G}$ & 28 & 30.4 & 33 & 17.9 & 1.997 & 1.109-3.587 & 0.021 \\
\hline Total & 92 & 100 & 184 & 100 & & & \\
\hline
\end{tabular}

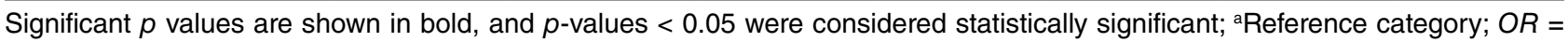
odds ratio; $\mathrm{Cl}=$ confidence interval. The $p$-value was calculated by the Chi-squared test $\left(\chi^{2}\right)$. The Akaike information criteria in the codominant model to rs1135216 genotype GG: 11.088

Table 3 - Analysis of the inheritance models considering the SNPs (1177A>G, 2090A>G) in the TAP1 gene

\begin{tabular}{|c|c|c|c|c|c|c|c|c|c|}
\hline \multirow{2}{*}{ SNPS } & \multirow{2}{*}{ Genotype } & \multicolumn{2}{|c|}{ Cases } & \multicolumn{2}{|c|}{ Controls } & \multirow{2}{*}{ OR } & \multirow{2}{*}{$95 \% \mathrm{Cl}$} & \multirow{2}{*}{$p$} & \multirow{2}{*}{ Akaike } \\
\hline & & $\mathrm{n}$ & $\%$ & $\mathrm{n}$ & $\%$ & & & & \\
\hline \multicolumn{10}{|c|}{ 1177A>G (rs1057141) } \\
\hline \multirow{2}{*}{ Dominant } & $\mathrm{AA}^{\mathrm{a}}$ & 23 & 50 & 56 & 60.9 & 1.0 & & & \\
\hline & $A G+G G$ & 23 & 50 & 36 & 39.1 & 1.551 & $0.755-3.193$ & 0.232 & \\
\hline \multirow{2}{*}{ Recessive } & $A A+A G^{a}$ & 39 & 84.8 & 86 & 93.5 & 1.0 & & & \\
\hline & GG & 7 & 15.2 & 6 & 6.5 & 2.553 & $0.778-8.591$ & 0.121 & \\
\hline Additive & & & & & & 0.647 & $0.382-1.095$ & 0.105 & \\
\hline \multicolumn{10}{|c|}{$2090 A>G($ rs1135216) } \\
\hline \multirow{2}{*}{ Dominant } & $\mathrm{AA}^{\mathrm{a}}$ & 25 & 54.4 & 61 & 66.3 & 1.0 & & & \\
\hline & $A G+G G$ & 21 & 45.7 & 31 & 33.7 & 1.647 & $0.793-3.421$ & 0.180 & \\
\hline \multirow{2}{*}{ Recessive } & $A A+A G^{a}$ & 39 & 84.8 & 90 & 97.8 & 1.0 & & & \\
\hline & $\mathrm{GG}$ & 7 & 15.2 & 2 & 2.2 & 7.945 & $1.684-57.97$ & 0.007 & 11.514 \\
\hline Additive & & & & & & 0.526 & $0.297-0.930$ & 0.027 & 18.436 \\
\hline
\end{tabular}

SNPs = single nucleotide polymorphisms; a Reference category; OR = odds ratio, $95 \% \mathrm{Cl}$ confidence interval. Significant $p$ values are shown in bold, and $p$-values $<0.05$ were considered statistically significant. The $p$-value was calculated by the Chi-squared test $\left(\chi^{2}\right)$. The Akaike information criteria were calculated for the polymorphisms presenting with more than one inheritance model and that had statistical significance.

of LTBI in our study population could be attributed to overcrowding, reported as a risk factor for $\mathrm{TB}^{15}$.
Other risk factors have been associated with the development of TB, such as host genetic factors. Studies 
have shown that genetic polymorphisms play a crucial role in the establishment and progression of active $\mathrm{TB}^{16}$. Polymorphisms in the TAP gene may lead to low translocation of peptides, altering the MHC-I pathway ${ }^{17}$.

The allele frequencies obtained in the present study (Table 2) coincide with those reported in the 1000-Genome project, $r \mathrm{~s} 1057141(\mathrm{G}=18.8 \%), \mathrm{rs} 1135216(\mathrm{G}=19.5 \%)$.

The rs 1135216 polymorphism $(2090 \mathrm{~A}>\mathrm{G})$ was associated with susceptibility to LTBI (OR=1.997, 95\% CI=1.109$3.587, p=0.021$ ), coinciding with results from other studies. A study on the Li population in China showed an association between the rs1135216 polymorphism ( $\mathrm{OR}=2.87,95 \%$ $\mathrm{CI}=1.75-4.71, p=<0.0001)$ in the TAPl gene, in patients with active TB versus control subjects ${ }^{6}$, and a study on an Iranian population found an association with the rs 1135216 polymorphism for an increased TB risk $(\mathrm{OR}=2.65,95 \%$ $\mathrm{CI}=1.78-396, p=<0.0001$ ), but not with $\mathrm{rs} 1057141^{8}$. In contrast, a Korean population study found no association with TB for those bearing TAPl gene polymorphisms? .

Furthermore, some polymorphisms have been associated with susceptibility to infections by other pathogens. Our group has recently found an association between a TAPI gene polymorphism with recurrent respiratory papillomatosis ${ }^{18}$. Other studies on polymorphisms in the TAP gene have reported an increased susceptibility to hepatitis $B$ virus (HBV), HIV and human papillomavirus (HPV) infections ${ }^{19,20}$.

In the codominant inheritance model of the 2090A $>\mathrm{G}$ polymorphism ( $\mathrm{rs} 1135216)$, the $\mathrm{G}$ allele $(\mathrm{OR}=8.328,95 \%$ $\mathrm{CI}=1.722-61.98, p=0.007$ ) was associated with an 8.3 -fold increased risk. These results are consistent with the ones reported by Naderi et al. ${ }^{8}$, who found that the polymorphic homozygote genotype $\mathrm{GG}(\mathrm{OR}=19.13,95 \% \mathrm{CI}=2.47-148.2$, $p=<0.001$ ) was associated with an increased risk of TB, compared with AA.

When the haplotype frequencies of TAPl were compared, no statistically significant differences were found, thus these haplotypes were not related to protection, i.e, a reduced susceptibility to LTBI in our study population. According to the haplotype analysis, the results resemble those of the report by Balladares et al..$^{21}$ in a Mexican mestizo and Seri Sonora Indian population.

TAP1 gene association studies have focused on active TB due to its relevance, but we believe that it is also essential to study the population with LTBI. At any rate, the role of both conditions and their associations with TAPl gene polymorphisms are unknown in the Mexican population.

\section{CONCLUSION}

In summary, the results suggested that the rs 1125216 $\mathrm{A}>\mathrm{G}$ polymorphism in TAPI is associated with the risk of LTBI. The present study is the first to analyze genetic variants in subjects with LTBI, and it is also the first study of this in a Mexican population. Nevertheless, this was a pilot study, and future studies are needed to explain the association of these TAP1 gene polymorphisms with LTBI and their possible implication in the establishment and progression of to TB.

\section{REFERENCES}

1. World Health Organization. Tuberculosis and HIV. [cited 2021 Jun 5]. Available from: https://www.who.int/hiv/topics/tb/ about_tb/en/

2. México. Secretaría de Salud. Dirección General de Epidemiología. Boletín epidemiológico: Sistema Nacional de Vigilancia Epidemiológica, Sistema Único de Información: semana 53, del 27 de diciembre del 2020 al 2 de enero del 2021. [cited 2021 Jun 5]. Available from: https://www.gob.mx/cms/uploads/ attachment/file/614743/sem53.pdf

3. Pai M, Behr MA, Dowdy D, Dheda K, Divangahi M, Boehme CC, et al. Tuberculosis. Nat Rev Dis Primers. 2016;2:16076.

4. O'Garra A, Redford PS, McNab FW, Bloom CI, Wilkinson RJ, Berry MP. The immune response in tuberculosis. Annu Rev Immunol. 2013;31:475-527.

5. Lawn SD, Zumla AI. Tuberculosis. Lancet. 2011;378:57-72.

6. Wang D, Zhou Y, Ji L, He T, Lin F, Lin R, et al. Association of LMP/TAP gene polymorphisms with tuberculosis susceptibility in Li population in China. PLoS One. 2012;7: e33051.

7. Roh EY, Yoon JH, Shin S, Song EY, Park MH. Association of TAP1 and TAP2 genes with susceptibility to pulmonary tuberculosis in Koreans. APMIS. 2015;123:457-64.

8. Naderi M, Hashemi M, Amininia S. Association of TAP1 and TAP2 gene polymorphisms with susceptibility to pulmonary tuberculosis. Iran J Allergy Asthma Immunol. 2016;15:62-8.

9. Monaco JJ. Structure and function of genes in the MHC class II region. Curr Opin Immunol. 1993;5:17-20.

10. Forrellad MA, Klepp LI, Gioffré A, Sabio y García J, Morbidoni HR, de la Paz Santangelo M, et al. Virulence factors of the Mycobacterium tuberculosis complex. Virulence. 2013;4:3-66.

11. Lewinsohn DM, Grotzke JE, Heinzel AS, Zhu L, Ovendale PJ, Johnson M, et al. Secreted proteins from Mycobacterium tuberculosis gain access to the cytosolic MHC-class-I antigenprocessing pathway. J Immunol. 2006;177:437-42.

12. Brookes RH, Pathan AA, McShane H, Hensmann M, Price DA, Hill AV. CD8+ T cell-mediated suppression of intracellular Mycobacterium tuberculosis growth in activated human macrophages. Eur J Immunol. 2003;33:3293-302.

13. Vigneron N, Van den Eynde BJ. Proteasome subtypes and regulators in the processing of antigenic peptides presented by class I molecules of the major histocompatibility complex. Biomolecules. 2014;4:994-1025. 
14. Pourakbari B, Mamishi S, Benvari S, Mahmoudi S. Comparison of the QuantiFERON-TB Gold Plus and QuantiFERON-TB Gold In-Tube interferon- $\gamma$ release assays: a systematic review and meta-analysis. Adv Med Sci. 2019;64:437-43.

15. Baker M, Das D, Venugopal K, Howden-Chapman P. Tuberculosis associated with household crowding in a developed country. $\mathrm{J}$ Epidemiol Community Health. 2008;62:715-21.

16. Ghanavi J, Farnia P, Farnia P, Velayati AA. Human genetic background in susceptibility to tuberculosis. Int J Mycobacteriol. 2020;9:239-47.

17. Van Kaer L, Ashton-Rickardt PG, Ploegh HL, Tonegawa S. TAP1 mutant mice are deficient in antigen presentation, surface class-I molecules, and CD4-8 + T cells. Cell. 1992;71:1205-14.

18. Palomares-Marin J, Govea-Camacho LH, Araujo-Caballero V, Cazarez-Navarro G, Rodriguez-Preciado SY, OrtizHernandez E, et al. Association between the TAP1 gene polymorphisms and recurrent respiratory papillomatosis in patients from Western Mexico: a pilot study. J Clin Lab Anal. 2021;35:e23712.

19. Qiu B, Huang B, Wang X, Liang J, Feng J, Chang Y, et al. Association of TAP1 and TAP2 polymorphisms with the outcome of persistent HBV infection in a northeast Han Chinese population. Scand J Gastroenterol. 2012;47:1368-74.

20. Abitew AM, Sobti RC, Sharma VL, Wanchu A. Analysis of transporter associated with antigen presentation (TAP) genes polymorphisms with HIV-1 infection. Mol Cell Biochem. 2020;464:65-71.

21. Balladares S, Alaez C, Pujol J, Duran C, Navarro JL, Gorodezky C. Distribution of TAP gene polymorphisms and extended MHC haplotypes in Mexican Mestizos and in Seri Indians from northwest Mexico. Genes Immun. 2002;3:78-85. 